\title{
Sesamin Protects Against Cardiac Remodeling Via Sirt3/ROS Pathway
}

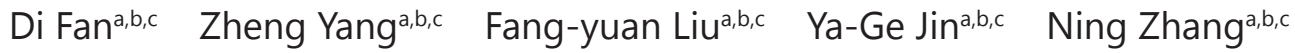 \\ Jian Nia,b,c Yuan Yuan ${ }^{a, b, c}$ Hai-Han Liao ${ }^{a, b, c}$ Qing-Qing Wu $u^{a, b, c}$ Man Xu $u^{a, b, c}$ \\ Wei Deng ${ }^{a, b, c}$ Qi-Zhu Tang ${ }^{a, b, c}$
}

aDepartment of Cardiology, Renmin Hospital of Wuhan University, Wuhan, ${ }^{b}$ Cardiovascular Research Institute of Wuhan University, Wuhan, 'Hubei Key Laboratory of Cardiology, Wuhan, China

\section{Key Words}

Sesamin - Sirtuin 3 - Cardiac hypertrophy - Reactive oxygen species - Mitogen-activated protein kinase $\cdot$ Inflammation

\begin{abstract}
Background/Aims: Cardiac remodeling is associated with oxidative stress. Sesamin, a wellknown antioxidant from sesamin seeds, have been used extensively as traditional health foods. However, there is little known about the effect of sesamin on cardiac remodeling. Therefore, the present study aimed to determine whether sesamin could protect against cardiac remodeling and to clarify potential molecular mechanisms. Methods: The mice were subjected to either transverse aortic constriction (TAC) or sham surgery (control group). Beginning one week after surgery, the mice were oral gavage treated with sesamin $\left(100 \mathrm{mg} \cdot \mathrm{kg}^{-1} \cdot \mathrm{day}^{-1}\right)$ or vehicle for 3 weeks. Cardiac hypertrophy was assessed by echocardiographic parameters, histological analyses and hypertrophic markers. Results: Sesamin alleviated cardiac hypertrophy, inhibited fibrosis and attenuated the inflammatory response. The increased production of reactive oxygen species, the activation of ERK1/2-dependent nuclear factor- $\kappa \mathrm{B}$ and the increased level of Smad2 phosphorylation were observed in cardiac remolding model that were treated with sesamin. Furthermore, TAC induced alteration of Sirt3 and SOD2 was normalized by sesamin treatment. Finally, a selective Sirt3 inhibitor 3-TYP blocks all the protective role of sesamin, suggesting that a Sirt3-dependent effect of sesamin on cardiac remodeling. Conclusion: Sesamin improves cardiac function and prevents the development of cardiac hypertrophy via Sirt3/ROS pathway. Our results suggest the protective effect of sesamin on cardiac remolding.

(C) 2017 The Author(s)

Published by S. Karger AG, Basel

\section{Introduction}

During the past half-century, heart failure is still an important global health problem with an estimated prevalence of 38 million patients worldwide, a number that is increasing with the ageing of the population [1]. Cardiac remodeling is usually accompanied by left ventricle (LV) geometry disruption, interstitial fibrosis, myocardial hypertrophy and vascular

D. Fan and Z. Yang contributed equally to this work.

Qi-Zhu Tang

and Wei Deng


dysfunction, leading to progressive diastolic and systolic heart failure [2, 3]. Therefore, clarify the underlying signaling pathways and the specific molecular mechanism may lead to new therapeutic strategies of delaying or even reverse the progress of the heart failure.

Reactive oxygen species (ROS) plays a key role in pressure overload or AngII induced cardiac hypertrophy [4-6]. Increasing ROS actives branches of the protein response inducing cardiac fibrosis, hypertrophic responses and vascular dysfunction, contributing to the process of cardiac hypertrophy [7]. Therefore, it is important to understand the regulatory mechanisms of oxygen stress and the effective way to prevent the accumulation of ROS. Sirt3 (sirtuin 3) is the primary mitochondrial acetyl-lysine deacetylase that modulates signal pathways to control ROS generation [8]. More importantly, Sirt3 directly binds and enhances the antioxidant activity of target substrate SOD2, which leads to a significant effect on ROS homeostasis [9]. Manganese superoxide dismutase (MnSOD, SOD2) is one of mitochondrial antioxidant enzymes to protect cells against oxidative damage, protecting the heart from oxidative injury and cardiac dysfunction [10-12]. Therefore, pharmacological interventions with Sirt3/ROS pathway could be of significant therapeutic interest for treating cardiac remodeling.

Sesamin, a furofuran-class lignin exacted from sesame seeds, is widespread in vascular plants and represented by Sesamum spp [13]. Sesamin has been reported to act as antioxidant, ameliorating oxidative stress and mortality in brain injury models by inhibition of MAPK and COX-2 activation [14]. Recently, it was reported that sesamin improved cardiac function in doxorubicin-induced cardiotoxicity model by Sirt1 and Mn-SOD pathway [15]. Moreover, sesamin attenuates nutritional fibrosing steatohepatitis by its anti-inflammatory and antifibrogenic actions [16]. According to these findings, there is a possibility that sesamin could protect against cardiac remodeling.

The present study investigated whether sesamin can attenuate pressure overload induced cardiac hypertrophy as well as fibrosis in mice, and to identify the molecular mechanisms responsible for these putative effects. We demonstrate that mice treated with sesamin reveal suppressed hypertrophic and fibrotic response. Sesamin-mediated upregulation of Sirt3 blocks cardiac remodeling response by suppressing ROS production and downstream signaling pathway.

\section{Materials and Methods}

Animal models and procedures

All the animal experimental protocols were approved by the Animal Care and Use Committee of Renmin Hospital of Wuhan University and were conducted in accordance with the National Institutes of Health (NIH) Guide for the Care and Use of Laboratory Animal.

Cardiac hypertrophy mouse models were established by TAC-induced pressure overload. Briefly, male mice (8 to 10 week-old, body weight: $23.5 \mathrm{~g}$ - 27.5g, NO: 11401300039269) were purchased from the Institute of Laboratory Animal Science, Chinese Academy of Medical Sciences (Beijing, China). All animals were allowed to acclimatize to the laboratory environment for one week. All surgeries and subsequent analyses were performed in a blinded fashion. Mice were anaesthetized with $3 \%$ pentobarbital sodium (Sigma) at a dose of $50 \mathrm{mg} \cdot \mathrm{kg}^{-1}$. Adequate anesthesia was confirmed by the absence of a toe pinch reflex. The procedure was performed according to Ji et al. [17]. We use temgesic $\left(0.1 \mathrm{mg} \cdot \mathrm{kg}^{-1}\right)$ once daily for 6 days postsurgery to treat post-operative pain. The control group for these animal experiments was given the same volume of liquid but consisted solely of the vehicle solution ( $0.5 \%$ carboxymethylcellulose). Beginning one week after surgery, we administered sesamin $\left(100 \mathrm{mg} \cdot \mathrm{kg}^{-1} \cdot \mathrm{day}^{-1}\right)$ by oral gavage for 3 weeks. At the end of the treatment, the surviving animals were randomly measured for cardiac function. Mice were euthanized with an overdose of sodium pentobarbital (200mg · kg-1; i.p.) and the hearts were collected.

Determination of sesamin in the tissues and serum

The mice were administered sesamin $\left(100 \mathrm{mg} \cdot \mathrm{kg}^{-1}\right)$ by oral gavage $(\mathrm{n}=10)$. The liver, lung, heart, kidney, brain and serum were collected at $0,3,6,9$, and $24 \mathrm{~h}$ after the administration. The liver, lung, heart, kidney, and brain samples were homogenized in 3 vol of distilled water. Sesamin was extracted from the 


\section{Cellular Physiology Cell Physiol Biochem 2017;44:2212-2227 \begin{tabular}{ll|l} 
and Biochemistry Published online: December 13, 2017 & $\begin{array}{l}\text { (c) } 2017 \text { The Author(s). Published by S. Karger AG, Basel } \\
\text { www.karger.com/cpb }\end{array}$
\end{tabular}}

Fan et al.: Sesamin Attenuates Cardiac Remodeling

homogenate solution and serum by the Bligh-Dyer method. Sesamin was analyzed using high-performance liquid chromatography (P230II, elitehplc). The ultraviolet detection wavelength for sesamin was $290 \mathrm{~nm}$.

\section{Echocardiography and haemodynamic evaluation}

Mice were anesthetized by inhalation of 1.5-2\% isoflurane. Echocardiography was performed to evaluate the structure and function of the left ventricle using a MyLab 30CV system (Biosound Esaote, Inc.) equipped with a 15-MHz probe. To measure the LV end-systolic diameter (LVESD), LV end-diastolic dimension (LVEDD), and LV fractional shortening (FS), M-mode tracings derived from the short axis of the left ventricle at the level of the papillary muscles were recorded; parameters were obtained from at least three beats and averaged. For the haemodynamic analysis, a 1.4-French catheter-tip micromanometer catheter (SPR-839; Millar Instruments, Houston, TX, USA) was inserted into the left ventricle via the right carotid artery to obtain invasive haemodynamic measurements. An aria pressure-volume conductance system (MPVS-300 Signal Conditioner, Millar Instruments, Houston, TX, USA) coupled with a PowerLab/4SP A/D converter was used to continuously record the heart rates, pressure, and volume signals.

\section{Morphological examination}

Four weeks after the surgery, following euthanasia, the heart, lung and tibia were collected for further analysis. The hearts were arrested with $10 \% \mathrm{KCl}$, fixed in $10 \%$ formalin, embedded in paraffin, and transversely sliced into 5- $\mu \mathrm{m}$ sections that were stained with haematoxylin-eosin (H\&E) or picrosirius red (PSR). Each slide was examined by two independent examiners. The fibrotic areas were measured using a digital image analysis system (Image-Pro Plus, version 6.0) from images captured from PSR-stained sections. For myocyte cross-sectional area, sections were stained for membranes with FITC-conjugated WGA (Invitrogen) and for nuclei with DAPI. A single myocyte was measured with an image quantitative digital analysis system (NIH Image, version 1.6). The outline of 150 myocytes was traced in each group.

\section{Quantitative real-time PCR and Western blot analysis}

Briefly, total RNA was extracted from mouse hearts using TRIzol (Invitrogen, 15596-026) on ice, and cDNA was generated with the Transcriptor First Strand cDNA Synthesis Kit (04897030001, Roche Diagnostics, Basel, Switzerland). Transcripts were later amplified using SYBR Green (Roche, 04707516001), and GAPDH served as the endogenous reference gene. (For all online suppl. material, see www.karger.com/ doi/10.1159/000486026, Table S1 show all primer details).

Protein extract and Western blotting were performed essentially as described previously [17]. Protein expression levels were normalized to the matched total proteins or GAPDH. GAPDH served as the loading control. All the details of primary antibodies were given (see online suppl. material) in Table S2.

\section{Cell culture and suface area}

Briefly, cardiac cells were isolated in PBS containing 0.03\% trypsin and $0.04 \%$ collagenase type II from the hearts of neonatal rats. Subsequently, neonatal rat cardiac myocytes (NRCMs) were purified by removing cardiac fibroblasts via a differential attachment technique. NRCMs were then seeded at a density of $2 \times 10^{5}$ cells per well in six-well culture plates. After $48 \mathrm{~h}$, the culture medium was replaced with serumfree DMEM/F12 for $12 \mathrm{~h}$ before stimulation with Ang II $(1 \mu \mathrm{M})$. For Sirt3 inhibition, NRCMs were incubated with 3-TYP $(50 \mu \mathrm{M})$ in the presence or absence of hypertrophic stimuli and sesamin $(10 \mathrm{mM})$ for $48 \mathrm{~h}$. H9C2 cardiomyocytes were obtained from the Cell Bank of the Chinese Academy of Sciences (Shanghai, China). Cells were seeded in DMEM (GIBCO (California, USA), C11995) supplemented with 10\% FBS (GIBCO, 10099), penicillin (100 U. $\left.\mathrm{mL}^{-1}\right)$ and streptomycin $\left(100 \mathrm{mg} \cdot \mathrm{mL}^{-1}\right)(\mathrm{GIBCO}, 15140)$. Cells below passage 15 were used. Cells were incubated with angiotensin II (Ang II; $1 \mu \mathrm{M}$ ) for $48 \mathrm{~h}$ after starvation with DMEM medium containing $0.5 \%$ FBS overnight to induce hypertrophy. For cells treated with sesamin, Sirt3 inhibitor or ROS scavenger, sesamin (10 mM), 3-TYP ( $50 \mu \mathrm{M})$, NAC $(10 \mathrm{mM})$ were added into the media before Ang II administration. To visualize the morphological change, H9C2 cells were fixed with $4 \%$ paraformaldehyde and permeabilized with $0.1 \%$ Triton-X100 and stained with rhodamine-phalloidin at a concentration of $50 \mathrm{ug} / \mathrm{ml}$ for $30 \mathrm{~min}$ at room temperature and washed with PBS and detected by fluorescence microscope (Tokyo, Japan). The surface areas were measured using Image-Pro Plus 6.0 software. The quantitative data for cell size of $>100$ randomly selected cells in 3 independent experiments. The cardiac fibroblasts were cultured in DMEM/F12 with 10\% FBS. CFs prior to the third passage were used in our study. 


\section{Cellular Physiology Cell Physiol Biochem 2017;44:2212-2227 \begin{tabular}{l|l|l} 
and Biochemistry Published onlIne: December 13, 2017 & $\begin{array}{l}\text { (c) } 2017 \text { The Author(s). Published by S. Karger AG, Basel } \\
\text { www.karger.com/cpb }\end{array}$ \\
\hline
\end{tabular}}

Fan et al.: Sesamin Attenuates Cardiac Remodeling

\section{ROS Measurement in vivo}

Production of ROS was evaluated by analyzing the fluorescence intensity that resulted from dihydroethidium (DHE) staining. In brief, frozen mouse hearts were cut into $5 \mu \mathrm{m}$ sections. Serial heart sections were stained with $5 \mu \mathrm{M} \mathrm{DHE}$ at $37^{\circ} \mathrm{C}$ for 30 minutes and then measured by fluorescence microscopy (Tokyo, Japan). Images were quantified using Image-Pro Plus 6.0.

\section{Statistical analyses}

Statistical analyses were performed using GraphPad Prism 5 (GraphPad) for PC. Quantitative data are expressed as mean \pm SEM unless otherwise stated. Comparisons between two groups were performed using Student's t test. Differences among groups were assessed using a one-way analysis of variance (ANOVA) followed by Tukey's post hoc test. For all statistical analyses, the level of significance was set at 0.05 .

\section{Materials}

Sesamin (\#607-80-7) was obtained from Shanghai Winherb Medical Science Co (Shanghai, China, www. sh-winherb.com/Zproduct.aspx?fn=2\&key=sesamin). The purity of sesamin was above $99 \%$ determined by HPLC analysis. Angiotensin II (Ang II, A9525) and N-acetyl-L-cysteine (NAC, A7250) were purchased from Sigma-Aldrich (St. Louis, MO, USA). DAPI (S36939) and FITC-conjugated WGA were purchased from Invitrogen. DHE were obtained from Keygen Biotech. 3-(1H-1, 2,3-triazol-4-yl)pyridine (3-TYP, HY-108331) were obtained from MedChemExpress. Proteins were measured with assay kits obtained from Pierce (Pierce, 23225). All other chemicals were of analytical grade.

\section{Results}

Sesamin improved cardiac function and attenuated cardiac hypertrophy in vivo

We examined concentration of sesamin in the tissues and serum, and found that sesamin has the high concentration in heart, liver and lung after oral gavage administration, which implies us that sesamin is most likely to have some effort in the these organs (see online suppl. material, Fig. S1). We investigated the effects of sesamin in a murine model of cardiac hypertrophy. All vehicle-treated demonstrated the marked increase in heart size and dilatation of ventricular chambers as compared with the sham control group after 4 weeks post-surgery. In contrast, Sesamin treatment of the TAC mice had a significant reduction in hypertrophic growth as measured by HW/BW and HW/TL (Fig. 1A), without affecting body weight, heart rate (see online suppl. material, Fig. S2A \& S2B). No significant differences were observed in the sham operated mice treated with sesamin or vehicle (Fig. 1A). The effect of sesamin on cardiac remodeling after TAC was further confirmed by Gross heart, HE staining and WGA staining (Fig. 1B \& 1C). In accordance with reduced cardiac hypertrophy examined by HE staining and WGA staining, mRNA levels of atrial natriuretic peptide (ANP), B-type natriuretic peptide (BNP), and $\beta$-myosin heavy chain ( $\beta$-MHC) were markedly suppressed in mice by treatment with sesamin (Fig. 1D). Sesamin treatment prevented the development of adverse cardiac remodelling and ventricular dysfunction, as demonstrated by decreased LVESD, LVEDD and percent fractional shortening (\%FS) (Fig. 1E \& Fig. 1F). According to the pressure-volume analysis, we find that systolic function (assessed by $+\mathrm{dP} / \mathrm{dt}$ ) and diastolic function (assessed by $-\mathrm{dP} / \mathrm{dt}$ ) were improved after treatment with sesamin (Fig. 1G). The LV pressure-volume loops also showed preserved systolic function in sesamin-treated mice compared with the vehicle-treated mice in the TAC groups (see online suppl. material, Fig. 2SC). These results suggest that sesamin could improve cardiac function and suppress cardiac hypertrophy after TAC surgery.

\section{Sesamin attenuate cardiac fibrosis in vivo}

To investigate the mechanism by which sesamin inhibits cardiac hypertrophy further, we examined the ability of sesamin to inhibit fibrosis. Compared with the vehicle-treated group, mice with sesamin presented a marked reduction in LV collagen volume examined by Sirius red staining after TAC surgery (Fig. 2A). To examine the molecular mechanisms of 


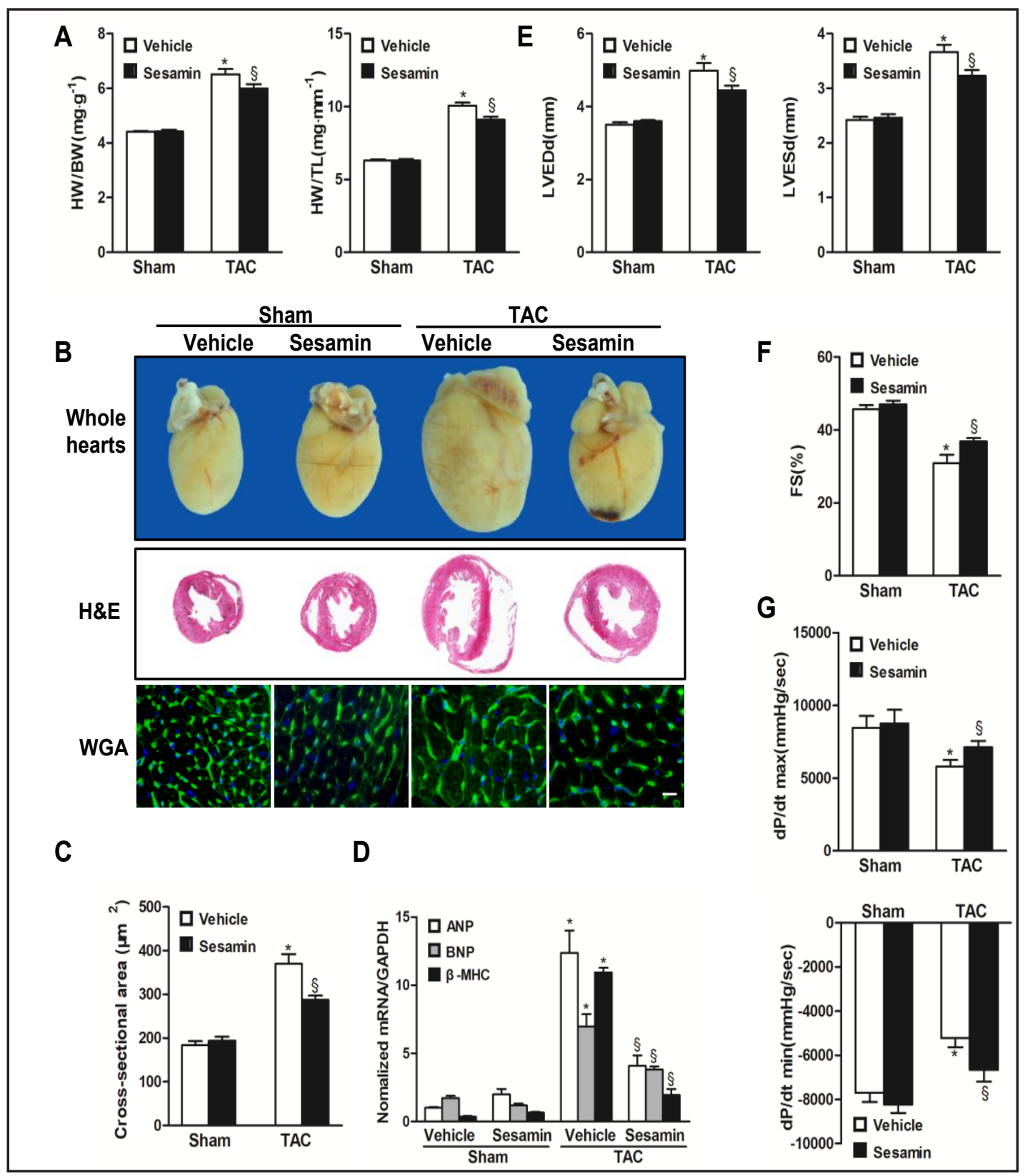

Fig. 1. Sesamin improved cardiac function and attenuated cardiac hypertrophy in vivo. (A) Statistical results of HW/BW ratio, HW/TL ratio at 4 weeks after TAC surgery $(\mathrm{n}=10)$. (B) Gross heart and HE staining and WGA-FITC of sham and TAC mice at 4 week after surgery in treatment by vehicle and sesamin mice $(n=6)$. (C) Quantification of the cardiomyocyte cross-sectional area $(n=6)$. (D)Analysis of hypertrophic markers in left ventricular samples $(n=6)$. ( $E$ and F) Left ventricle end-diastolic diameter (LVEDD), left ventricle endsystolic diameter (LVESD) and fractional shortening (FS) were collected from echocardiographic $(n=6) .(G)$ Maximal rate of pressure development ( $\mathrm{dP} / \mathrm{dt} \max )$ and minimal rate of pressure decay $(\mathrm{dP} / \mathrm{dt} \min )$ were calculated from the pressure-volume loop data $(n=10)$. Values represent the mean $\pm S E M$. ${ }^{*} P<0.05$ versus Sham/vehicle group; ${ }^{\S} \mathrm{P}<0.05$ versus TAC/vehicle group.

sesamin in collagen synthesis, we assessed the effect of sesamin on Smad cascade activation. The increased levels of TGF- $\beta 1$ and Smad 2 phosphorylation were attenuated in sesamintreated mice after TAC surgery (Fig. 2B \& 2C). Subsequent analysis of the expression of 


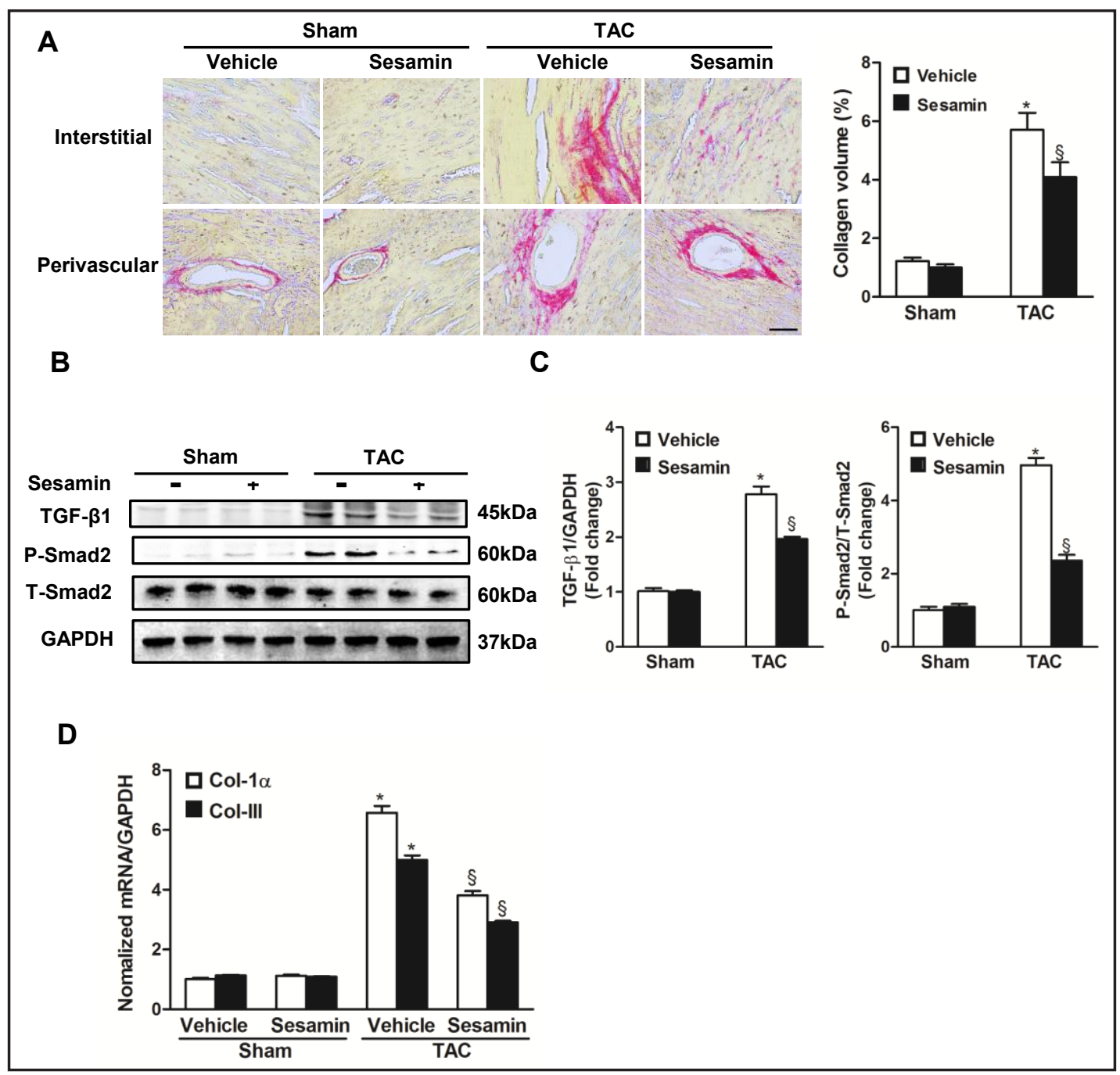

Fig. 2. Sesamin attenuate cardiac fibrosis in vivo. (A) PSR staining on histological sections of the LV was performed on indicated mice 4 weeks after TAC (scale bar, $400 \mu \mathrm{m}$ ). Fibrotic areas from histological sections were quantified using an image analyzing system. (B and C) Representative blots of TGF- $\beta 1$, Smad2 phosphorylation and Smad2 from indicated groups $(n=6)$. (D) Real-time PCR analyses of fibrosis-related genes $(n=6) .{ }^{*} \mathrm{P}<0.05$ versus Sham/vehicle group; ${ }^{\S} \mathrm{P}<0.05$ versus TAC/vehicle group.

fibrotic markers, such as collagen I and collagen III, demonstrated a suppression response following sesamin administration compared with the vehicle-treated group (Fig. 2D). These results indicate that mice by treatment with sesamin show a limitation in fibrotic response induced by chronic pressure overload stimuli.

\section{Sesamin inhibits inflammatory responses following chronic pressure overload}

It has been reported that inflammation plays an important role in the development of cardiac and vascular diseases [18]. To determine the effect of sesamin on inflammatory responses, we examined whether sesamin affects NF-kB signalling in the heart. Compared with vehicle-treated mice 4 weeks post-TAC, the elevated phosphorylation level of the NF- $\kappa B$ family member p65 were suppressed in mice by treatment with sesamin (Fig. 3A \& 3B). IкB $\alpha$, as a NF- $\mathrm{BB}$ inhibitor [19], was examined in our study. According to western blot analysis, I $\mathrm{\kappa} \mathrm{B} \alpha$ phosphorylation and $\mathrm{I} \kappa \mathrm{B} \alpha$ degradation in vehicle-treated TAC mice was significantly impaired after treatment with sesamin (Fig. 3A \& 3B). Furthermore, we examined the expression of inflammatory mediators IL-6, tumor necrosis factor $\alpha$ (TNF- $\alpha$ ) 


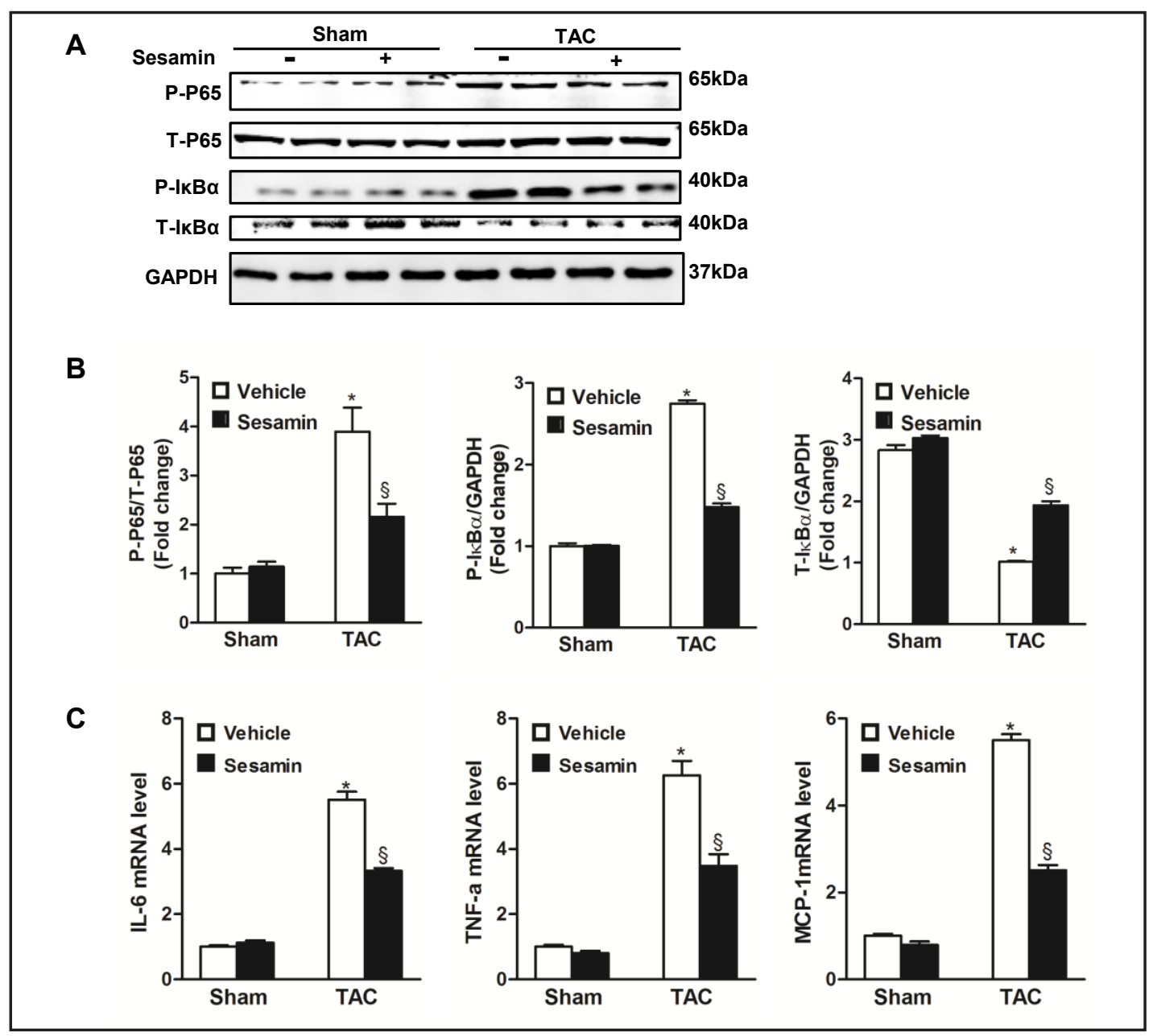

Fig. 3. Sesamin inhibits inflammatory responses following chronic pressure overload. (A and B) Western

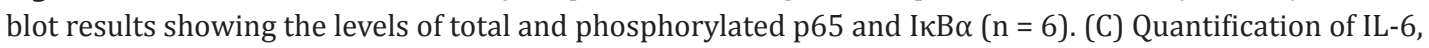
TNF- $\alpha$ and MCP-1 mRNA levels by use of real-time PCR $(n=6)$. Values represent the mean \pm SEM. ${ }^{*} \mathrm{P}<0.05$ versus Sham/vehicle group; ${ }^{\circledR} \mathrm{P}<0.05$ versus TAC/vehicle group.

and monocyte chemoattractant protein-1 (MCP-1) in cardiac tissue. Our results showed that sesamin significantly decreased the mRNA levels of IL-6, TNF- $\alpha$ and MCP-1 compared with vehicle-treated TAC mice (Fig. 3C). These results indicate that sesamin inhibits inflammation by blocking NF- $\kappa \mathrm{B}$ signalling in response to chronic pressure overload.

Sesamin inhibits MEK-ERK1/2 signalling in vitro and in vivo, but not noncanonical TGF- $\beta$ signalling

Many studies have shown that MAPK signaling pathway is a key contributor to the development of cardiac hypertrophy $[20,21]$. Therefore, we examined whether MAPK was responsible for anti-hypertrophy effects of sesamin. We excitingly observed that TAC induced a significant activation of the MAPK pathway. However, sesamin treatment markedly suppressed the activation of MEK and ERK1/2, whereas $\mathrm{p} 38$ and JNK1/2 were not significantly affected (Fig. 4A \& 4B). Next, we exposed neonatal rat cultured cardiac myocytes to $1 \mu \mathrm{M}$ Ang II for $48 \mathrm{~h}$ with or without $10 \mu \mathrm{M}$ sesamin. In line with the in vivo findings, Ang II induced a significant increase in phosphorylated levels of MEK, ERK1/2, p38 and JNK. Nevertheless, activation of MEK and ERK1/2 were blocked by sesamin, not that of p38 or JNK (Fig. 4C \& $4 \mathrm{D})$. According to previous findings, myocyte-targeted noncanonical TGF- $\beta$ signaling plays 
A

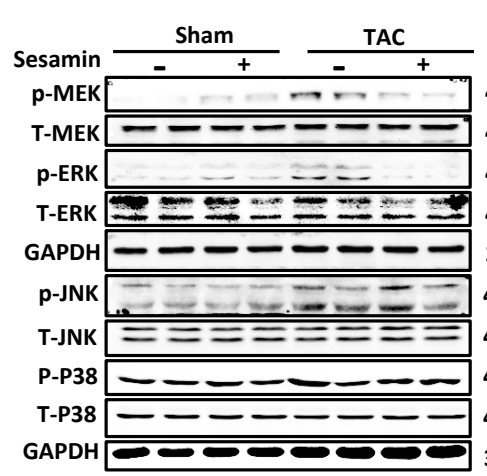

C

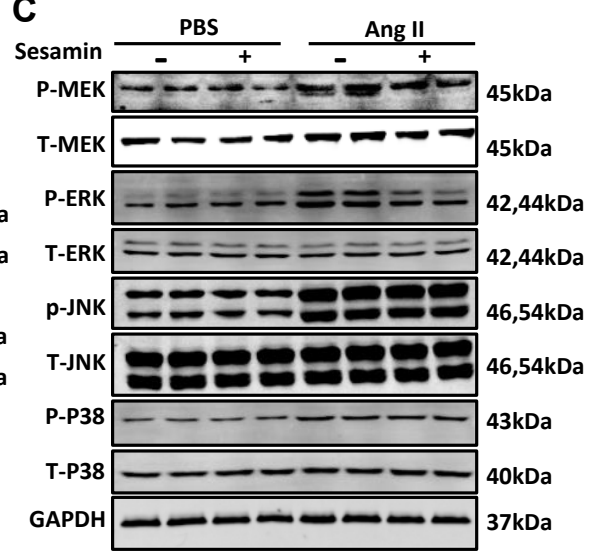

B $45 \mathrm{kDa}$ $45 \mathrm{kDa}$ $42,44 \mathrm{kDa}$ $42,44 \mathrm{kDa}$ $37 \mathrm{kDa}$ $46,54 \mathrm{kDa}$ $46,54 \mathrm{kDa}$ $43 \mathrm{kDa}$ 40kDa $37 \mathrm{kDa}$
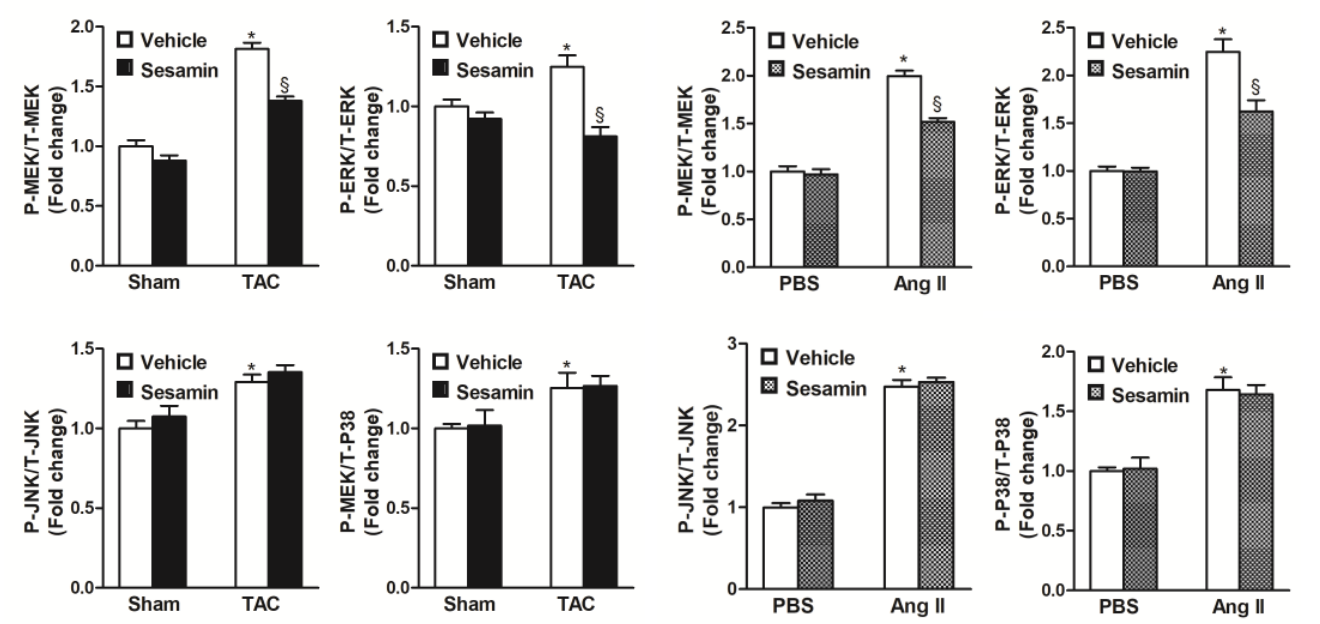

Fig. 4. The effects of sesamin on MAPK signaling in vitro and in vivo. (A and B) Western blots of MEK, ERK1/2, p38 and JNK1/2 phosphorylation and their total protein expression in the indicated groups of mice $(\mathrm{n}=6)$. ${ }^{*} \mathrm{P}<0.05$ versus Sham/vehicle group; ${ }^{\S} \mathrm{P}<0.05$ versus TAC/vehicle group. ( $C$ and $\mathrm{D}$ ) The effects of sesamin (10 mM) on MEK, ERK1/2, p38 and JNK1/2 phosphorylation and their total protein expression in cardiomyocytes treated with Ang II for $48 \mathrm{~h}(\mathrm{n}=6)$. Values represent the mean $\pm \mathrm{SEM}$. " $\mathrm{P}<0.05$ versus corresponding control; ${ }^{\S} \mathrm{P}<0.05$ versus the matched group.

a central role in the maladaptive cardiac response to sustained pressure overload [22]. To examine the effect of sesamin on noncanonical TGF- $\beta$ signalling in the heart, expression of TR $\beta 2$ and p-TAK1 was detected by Western blot (see online suppl. material, Fig. S3A \& S3B). Sesamin did not affect the expression of TR 32 and phosphorylation of TAK1. Oxidative stress has been demonstrated to upregulate TGF-b1 and cause structural remodelling [23]. Therefore, we checked whether the antioxidative properties of sesamin responsible for the downregulation of TGF- $\beta 1$ expression. Ang II-induced TGF- $\beta 1$ expression was decreased significantly in NAC treatment cells and treatment with sesamin did not further decrease TGF-b1 expression in cells (see online suppl. material, Fig. S3C \& S3D). Taken together, our results showed that sesamin treatment inhibits MEK-ERK1/2 signalling in vitro and in vivo, but did not affect noncanonical TGF- $\beta$ signaling, as well as the attenuation of AngII-induced secretion of TGF- $\beta 1$ by neonatal rat cardiac fibroblasts was dependent on antioxidative properties of sesamin. 


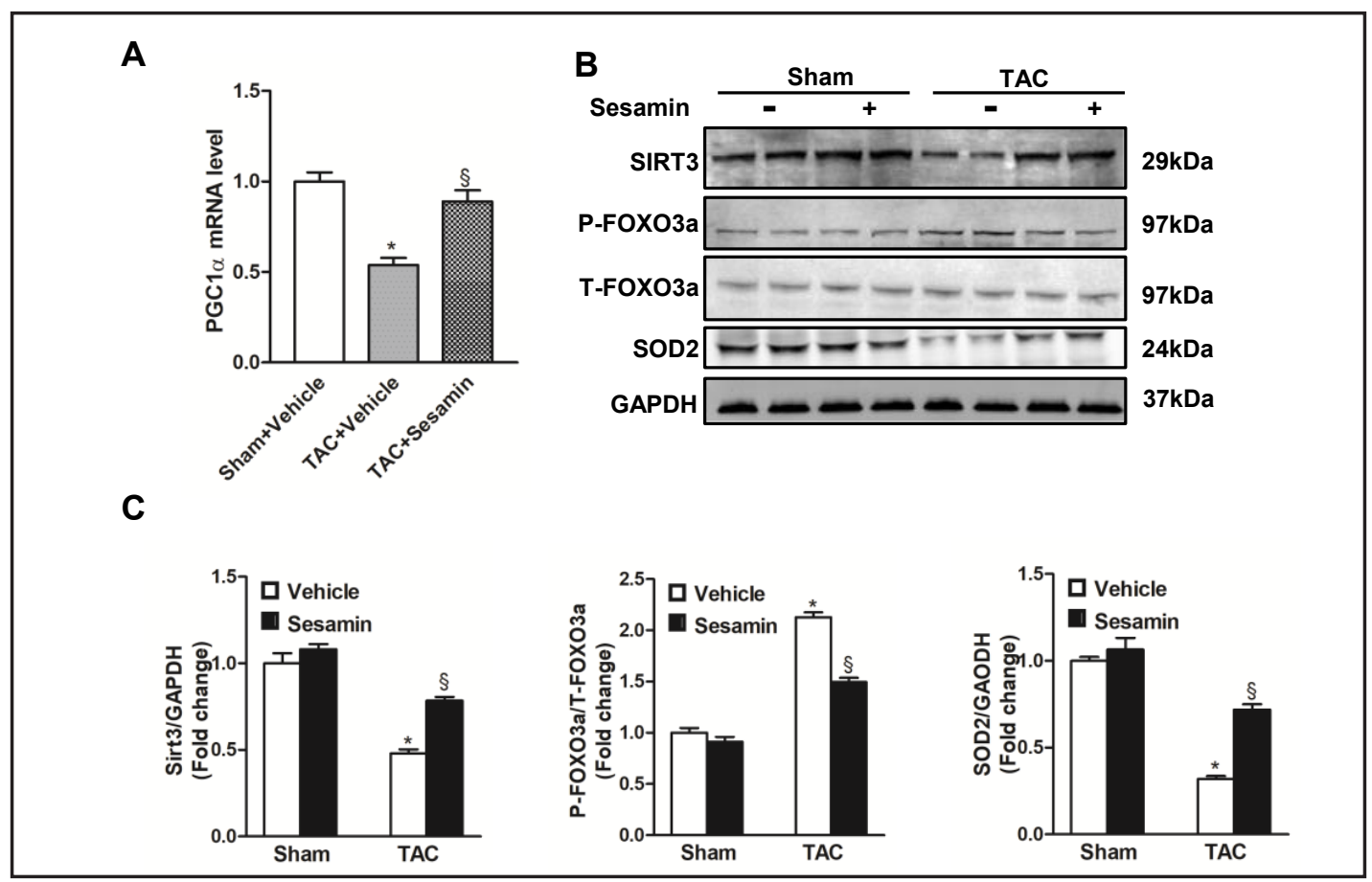

Fig. 5. Sesamin increase Sirt3 levels and its downstream signaling. (A) Real-time PCR analyses of PGC-1 $\alpha$ genes $(n=6)$. (C) The expression of Sirtuin 3 (SIRT3), superoxide dismutase 2 (SOD2), p-FOXO3a and total protein were detected by western blots $(n=6)$. ${ }^{*} \mathrm{P}<0.05$ versus Sham/vehicle group; $\S \mathrm{P}<0.05$ versus TAC/ vehicle group.

\section{Sesamin increase Sirt3 levels and its downstream signaling}

Previous studies have demonstrated that Sesamol, a liposoluble lignan extraction and prominent fragrance component in sesame oil, can improve PGC- $1 \alpha$ genes expressions [24], which can activates Sirt3 gene promoter, leading to increase synthesis of Sirt3 mRNA transcripts [25]. Moreover, another finding suggested that Sirt3 is downregulated during severe hypertrophy and heart failure, and the overexpression of Sirt3 blocks cardiac hypertrophy by enhancing the activities of antioxidants SOD2, which thereby reduce the cellular ROS levels [26]. Thus, we examined PGC- $1 \alpha$ mRNA and found that PGC-1 $\alpha$ mRNA was downregulated after TAC surgery, but normalized by sesamin treatment (Fig. 5A).We further measured Sirt3 and its downstream signaling expression levels. Sesamin restored the pressure overload-mediated reduction in Sirt3. As expected, sesamin significantly blocked the pressure overload-induced Foxo3a phosphorylation and expression of SOD2 (Fig. 5B \&5C). Collectively, these studies suggest that sesamin is capable of activating Sirt3 and its downstream signaling in vivo.

Sesamin attenuated reactive oxygen species generation via Sirt3 during cardiac hypertrophy

Oxidative stress is well known to play a crucial role in cardiac hypertrophy and remodeling $[27,28]$. Furthermore, sesamin is a biologically active compound with anti-oxidative [29]. Thus, we determined whether sesamin treatment could also decrease ROS levels in the response to hypertrophic stimuli. To this end, we assessed ROS levels in the hearts of mice. The results showed that chronic pressure overload induced an increase in total ROS levels (superoxide measured by dihydroethidium (DHE) staining) in TAC mice treated with vehicle, whereas this effect was significantly suppressed in mice with sesamin treatment (Fig. 6A). H9C2 exposed to Angiotensin II $(1 \mu \mathrm{M})$ show a greater increase in ROS levels detected by dihydroethidium (DHE) staining, whereas this effect was significantly suppressed in the cell

\section{KARGER}




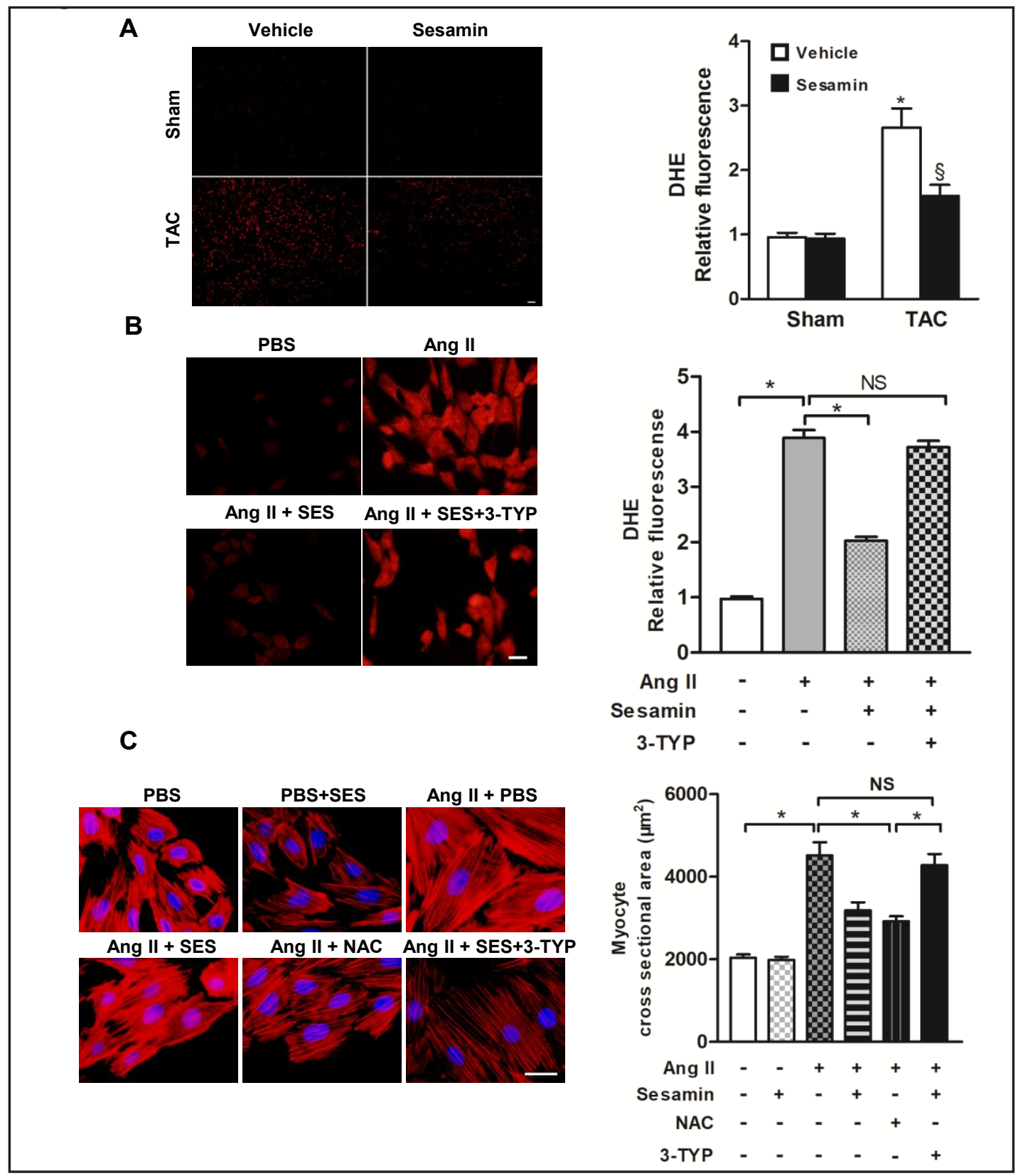

Fig. 6. Sesamin attenuated reactive oxygen species generation via Sirt3 during cardiac hypertrophy. (A) Measurement of reactive oxygen species levels in the hearts following TAC with or without sesamin treatment. Dihydroethidium staining were performed to assess total reactive oxygen species (scale bar, 100 $\mu \mathrm{m}, \mathrm{n}=6$ ). ${ }^{*} \mathrm{P}<0.05$ versus corresponding control; ${ }^{\S} \mathrm{P}<0.05$ versus the matched group. (B) Measurement

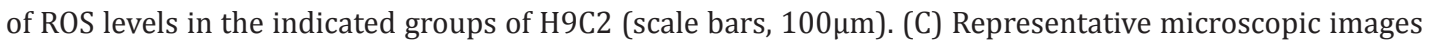
of H9C2 in the indicated groups. H9C2 were identified by rhodamine-phalloidin staining (red), and nuclei were stained with DAPI (blue). (Scale bars, $50 \mu \mathrm{m}$ ). Values represent the mean $\pm \mathrm{SEM} .{ }^{*} \mathrm{P}<0.05$ versus the matched control; NS: no significance.

treated with sesamin, but 3-TYP, a selective Sirt3 inhibitor, reversed the protective effects of sesamin on ROS production (Fig. 6B). To further prove the hypothesis, cell surface area analysis using rhodamine-phalloidin staining was performed. As shown in Fig. 6C, sesamin and NAC treatment dramatically attenuated the increase in cell growth induced by Ang II. H9C2 treated with Ang II + sesamin had a similar cell area compared with cardiomyocytes

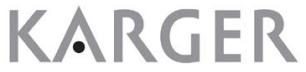




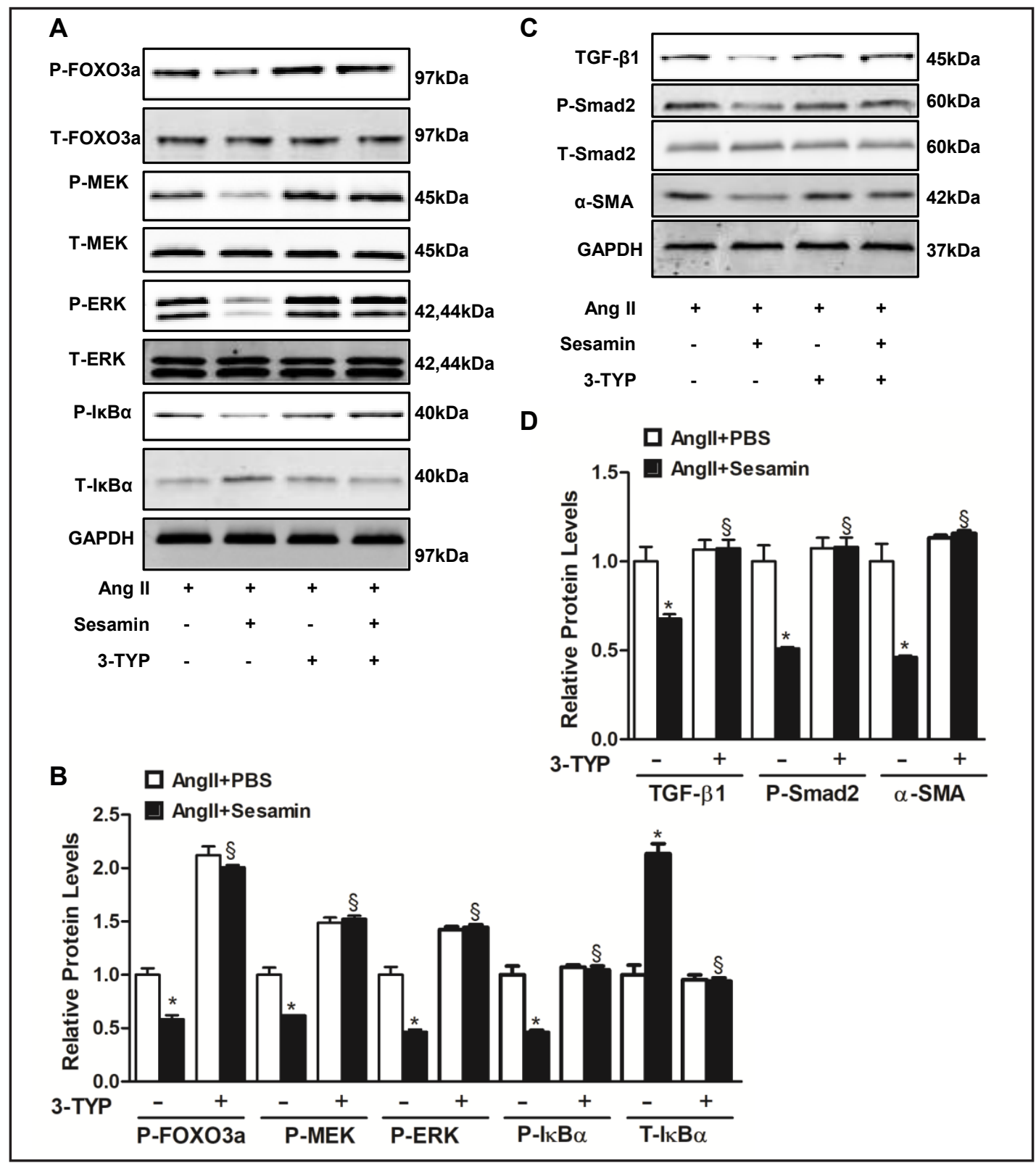

Fig. 7. Sesamin blocks the signaling pathways involved in development of cardiac hypertrophy attenuating ROS generation via Sirt3. (A) MEK, ERK1/2 and IкB $\alpha$ phosphorylation and their total protein expression were detected by Western blot. Cardiac myocytes were stimulated by Ang II for $48 \mathrm{~h}$ after treatment with sesamin $(10 \mathrm{mM})$ or 3-TYP $(50 \mu \mathrm{M})$. (B) Western blot analysis of TGF- $\beta 1$, Smad 2 phosphorylation and $\alpha$-SMA in CFs treated with Sesamin or 3-TYP, in the presence of Ang II. Values represent the mean \pm SEM. ${ }^{*} \mathrm{P}<0.05$ versus corresponding control; ${ }^{\S} \mathrm{P}<0.05$ versus the Ang II/3-TYP group.

with Ang II + NAC. Moreover, 3-TYP remarkably reversed the effects of sesamin on cell surface area (Fig. 6C). Collectively, our results indicated the effect of sesamin decreasing ROS levels and hypertrophic response by sesamin was dependent on a Sirt3/ROS pathway.

Sesamin blocks the signaling pathways involved in development of cardiac hypertrophy by attenuating ROS generation via Sirt3

To demonstrate that sesamin inhibited cardiac remodelling via the Sirt3 dependent attenuation of signaling pathways involved in development of cardiac hypertrophy, we 


\section{Cellular Physiology Cell Physiol Biochem 2017;44:2212-2227 \\ \begin{tabular}{l|l} 
DOI: 10.1159/000486026 & and Biochemistry \\
Published onlne: December 13, 2017 & $\begin{array}{l}\text { O 2017 The Author(s). Published by S. Karger AG, Basel } \\
\text { www.karger.com/cpb }\end{array}$
\end{tabular}}

Fan et al.: Sesamin Attenuates Cardiac Remodeling

incubated NRCMs with the selective Sirt3 inhibitor 3-TYP and found that the effects of sesamin were blocked by 3-TYP (Fig. 7A \& 7B). Ang II-induced phosphorylated levels of MEK, ERK1/2 and I $\mathrm{KB} \alpha$ was decreased significantly in N-acetylcysteine (NAC, $10 \mathrm{mM}$ ) treatment cells and treatment with sesamin did not further decrease phosphorylated levels of those in cells (see online suppl. material, Fig. S4A \& S4B), further supporting our hypothesis that sesamin exerted protective effects by reducing the ROS levels via Sirt3. Similarly, we also found that a Sirt3-dependent effect of sesamin on TGF- $\beta 1 /$ smad pathway in CFs exposed to Ang II (Fig. 7 C). Collectively, these data suggest that sesamin protects against cardiac remodeling via Sirt3/ROS pathway.

\section{Discussion}

The present study shows that sesamin not only protected against cardiac fibrosis, but also attenuated cardiac hypertrophy induced by pressure overload in vivo. Cardiac function of mice treatment with sesamin was preserved after chronic pressure overload (Fig. 1F \& G). The cardioprotective effects of sesamin were medicated by Sirt3, thus suppressing signaling pathways involved in development of cardiac hypertrophy, which resulted in restricted hypertrophy and fibrosis, ultimately improving cardiac performance.

Our study showed that sesamin not only improved cardiac performance, but also attenuated cardiac hypertrophic response in vivo. These findings are consistent with those from previous studies showing that sesamin decreases left ventricular remodeling in spontaneously hypertensive rats [30,31]. Although sesamin has been reported the beneficial effects on hypertension [32], we did not observe a reducing blood pressure in TAC mice treated with sesamin. However, several factors may account for this contradiction, including animal species and animal experimental models.

Cardiac fibrosis, associated with microvasculature destruction and disruption of normal myocardial structures, resulted in excessive deposition of extracellular matrix and electrical disturbances in diseased hearts, promoting the progression of heart failure [33]. Sesamin has been shown to possess anti-fibrotic effects in nutritional fibrosing steatohepatitis [16] and ovalbumin-induced airway fibrosis [34]. Therefore, we suppose that sesamin exerts anti-fibrotic effects in the hypertrophic hearts. Our study suggested that sesamin blocks TAC induced collagen synthesis in vivo. We examined TGF- $\beta /$ Smad signalling, as a key role in the progression of fibrosis $[35,36]$. We have found that mice with sesamin treatment attenuate the expression of TGF- $\beta 1$ and p-smad 2 induced by pressure overload, which is consistent with previous study [31]. Our data show that sesamin abrogates TGF- $\beta /$ Smad signalling in hypertrophied hearts and also inhibits collagen synthesis.

Mounting evidence has strongly suggested that inflammation plays a critical role in the development of cardiac hypertrophy and heart failure [37, 38]. Inflammatory Cytokines, such as TNF- $\alpha$, IL- 6 and MCP-1, which promote progression of cardiac hypertrophy and heart failure, increased in the hypertrophic hearts, were normalized by sesamin treatment. It is well known that NF- $\kappa \mathrm{B}$ signalling molecules are keys to control expression of several inflammatory cytokine genes [39]. Thus, the status of NF- $\kappa B$ signalling was examined in our study. The result showed that the chronic pressure overload induced activation of $\mathrm{p} 65$ was attenuated by sesamin treatment, and this effect is mediated by suppression of IкB $\alpha$ phosphorylation. These findings suggest that sesamin decreases the inflammatory response after TAC by NF- $\mathrm{KB}$ signalling, which may partially explain the protective effect of sesamin on cardiac inflammation and cardiac dysfunction after TAC surgery.

Reactive oxygen species affect almost all of the major features of cardiac maladaptive remodeling, including the hypertrophic responses, vascular dysfunction and extracellular matrix remodeling $[7,40]$. In our study, we found that TAC induced an increase in total ROS levels in the hearts, whereas this effect was substantially suppressed in mice with sesamin treatment. Nakamura et al. [41] reported that Ang II can lead to increasing ROS levels in cultured cardiac myocytes, whereas abolishment cardiomyopathy hypertrophy 
with antioxidants pre-treatment. It has been reported that Ang II-induced expression of the hypertrophic marker has also been reported to associate with ROS dependent activation of MAPK pathway [42]. Extensive research has shown that ROS also play a critical role in pressure overload induced hypertrophy [43]. Sirt3 plays a key role in control ROS homeostasis. Previous studies show that that Sirt3 is capable of blocking cardiac hypertrophy by reducing cellular ROS levels [26]. Another studies have demonstrated that Sesamol, a liposoluble lignan extraction and prominent fragrance component in sesame oil, can improve PGC- $1 \alpha$ genes expressions [24]. Moreover, Sirt3 functions as a downstream target gene of PGC- $1 \alpha$ and mediates the PGC- $1 \alpha$ effects on cellular ROS production and mitochondrial biogenesis [44]. All these findings imply that sesamin is capable of maintaining ROS homeostasis via Sirt3. It is worth mentioning that PGC- $1 \alpha$ has been shown to be downregulated in hypertrophied and failing hearts, which is consistent with the result that Sirt3 was reduced in TAC-induced cardiac hypertrophy [26]

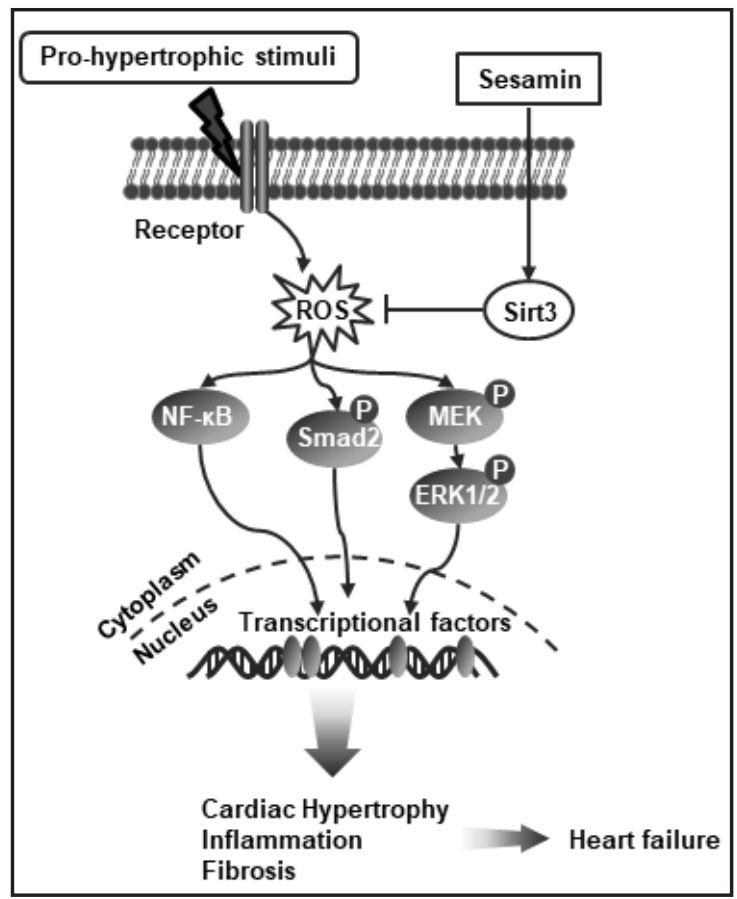

Fig. 8. Proposed model of the effect of sesamin on cardiac remodeling. Sesamin attenuates the level of ROS induced by hypertrophic stimulant via Sirt3. In our study, we have shown that sesamin suppresses all of Sirt3/ROS-dependent three proposed signalling pathways and then protects against fibrosis, inflammation and cardiac hypertrophy. [45]. We also have confirmed that PGC$1 \alpha$ mRNA was downregulated after TAC surgery, but normalized by sesamin treatment (Fig. 5A). Consist with previous studies [26], we found that sesamin treatment enhances Sirt3 and SOD2 expression, while decreasing phosphorylation levels of Foxo3a (Fig. 5B \&5C), suggesting that sesamin might be activation of Sirt3 to attenuate the ROS levels by activation of Foxo3a-dependent antioxidants and SOD2. Furthermore, sesamin significantly blocked the pressure overload-induced Foxo3a phosphorylation and expression of SOD2 (Fig. 5 B). We used Sirt3 inhibitor (3-TYP) to confirm that sesamin was involved in pressure overload-induced the disruption of Sir3regulated ROS production. As shown in Figures 7A, we incubated NRCMs with the selective Sirt3 inhibitor 3-TYP and found that the effects of sesamin were blocked by 3-TYP (Fig. 7A \& 7B). Similarly, we also found that a Sirt3-dependent effect of sesamin on TGF- $\beta 1 / \mathrm{smad}$ pathway in CFs exposed to Ang II (Fig. 7 C). In addition, 3-TYP also blocks the protective role of sesamin on decreasing ROS production and attenuating myocyte cross sectional area (Fig. $6 \mathrm{~B} \mathrm{\&} 6 \mathrm{C}$ ). Therefore, the mechanism of sesamin in protecting against cardiac remodeling is most probably through Sirt3/ROS pathway (Fig. 8).

\section{Conclusion}

In summary, we found that sesamin protect against cardiac hypertrophy, inflammation and fibrosis. Our data confirm that Sirt3 is a target of sesamin inhibitory actions. The probable mechanism of this action is mediated by ROS. Therefore, sesamin may offer a potentially effective and relatively safe approach for preventing cardiac remodelling induced by chronic pressure overload. 


\section{Acknowledgements}

This work was supported by grants from National Natural Science Foundation of China (No: 81270303, 81470516, 81470402, 81500184), the Key Project of the National Natural Science Foundation of China (No. 81530012) and Natural Science Foundation of Hubei Province, China (no. 2013CFB303, 2016CFB254).

DF, ZY, F-YL, Y-GJ, NZ, JN, YY, H-HL, Q-QW and MX performed the study, analyzed and interpreted the data, and wrote the manuscript. DF, ZY and F-YL contributed to acquisition of data and manuscript preparation and revision. DF, DW and Q-ZT conceived the hypothesis, participated in the experimental design, data interpretation, and manuscript preparation and revision. DF contributed to data collection and interpretation of data and manuscript drafting. All authors approved the final version of the manuscript. WD and Q-ZT are the guarantors of this work.

\section{Disclosure Statement}

The authors declare that there is no duality of interest associated with this manuscript.

\section{References}

1 Braunwald E: The war against heart failure: the Lancet lecture. Lancet 2015;385:812-824.

2 Shen S, Jiang H, Bei Y, Xiao J, Li X: Long Non-Coding RNAs in Cardiac Remodeling. Cell Physiol Biochem 2017;41:1830-1837.

-3 Belge C, Hammond J, Dubois-Deruy E, Manoury B, Hamelet J, Beauloye C, Markl A, Pouleur AC, Bertrand L, Esfahani H, Jnaoui K, Gotz KR, Nikolaev VO, Vanderper A, Herijgers P, Lobysheva I, Iaccarino G, HilfikerKleiner D, Tavernier G, Langin D, Dessy C, Balligand JL: Enhanced expression of beta3-adrenoceptors in cardiac myocytes attenuates neurohormone-induced hypertrophic remodeling through nitric oxide synthase. Circulation 2014;129:451-462.

4 Byrne JA, Grieve DJ, Bendall JK, Li JM, Gove C, Lambeth JD, Cave AC, Shah AM: Contrasting roles of NADPH oxidase isoforms in pressure-overload versus angiotensin II-induced cardiac hypertrophy. Circ Res 2003;93:802-805.

5 Hirotani S, Otsu K, Nishida K, Higuchi Y, Morita T, Nakayama H, Yamaguchi O, Mano T, Matsumura Y, Ueno H, Tada M, Hori M: Involvement of nuclear factor-kappaB and apoptosis signal-regulating kinase 1 in G-protein-coupled receptor agonist-induced cardiomyocyte hypertrophy. Circulation 2002;105:509-515.

6 Ma ZG, Dai J, Zhang WB, Yuan Y, Liao HH, Zhang N, Bian ZY, Tang QZ: Protection against cardiac hypertrophy by geniposide involves the GLP-1 receptor / AMPKalpha signalling pathway. Br J Pharmacol 2016;173:1502-1516.

7 Munzel T, Gori T, Keaney JF, Jr., Maack C, Daiber A: Pathophysiological role of oxidative stress in systolic and diastolic heart failure and its therapeutic implications. Eur Heart J 2015;36:2555-2564.

$>8$ Bause AS, Haigis MC: SIRT3 regulation of mitochondrial oxidative stress. Exp Gerontol 2013;48:634-639.

-9 Qiu X, Brown K, Hirschey MD, Verdin E, Chen D: Calorie restriction reduces oxidative stress by SIRT3mediated SOD2 activation. Cell Metab 2010;12:662-667.

10 Huang Q Zhou HJ, Zhang H, Huang Y, Hinojosa-Kirschenbaum F, Fan P, Yao L, Belardinelli L, Tellides G, Giordano FJ, Budas GR, Min W: Thioredoxin-2 inhibits mitochondrial reactive oxygen species generation and apoptosis stress kinase-1 activity to maintain cardiac function. Circulation 2015;131:1082-1097.

11 Loch T, Vakhrusheva O, Piotrowska I, Ziolkowski W, Ebelt H, Braun T, Bober E: Different extent of cardiac malfunction and resistance to oxidative stress in heterozygous and homozygous manganese-dependent superoxide dismutase-mutant mice. Cardiovasc Res 2009;82:448-457.

12 Nojiri H, Shimizu T, Funakoshi M, Yamaguchi O, Zhou H, Kawakami S, Ohta Y, Sami M, Tachibana T, Ishikawa H, Kurosawa H, Kahn RC, Otsu K, Shirasawa T: Oxidative stress causes heart failure with impaired mitochondrial respiration. J Biol Chem 2006;281:33789-33801. 


\section{Cellular Physiology Cell Physiol Biochem 2017;44:2212-2227 \begin{tabular}{l|l|l}
\hline and Biochemistry 10.1159/000486026 & $\begin{array}{l}\text { C } 2017 \text { The Author(s). Published by S. Karger AG, Basel } \\
\text { www.karger.com/cpb }\end{array}$ \\
\hline
\end{tabular}}

13 Ono E, Nakai M, Fukui Y, Tomimori N, Fukuchi-Mizutani M, Saito M, Satake H, Tanaka T, Katsuta M, Umezawa T, Tanaka Y: Formation of two methylenedioxy bridges by a Sesamum CYP81Q protein yielding a furofuran lignan, (+)-sesamin. Proc Natl Acad Sci U S A 2006;103:10116-10121.

$\checkmark 14$ Hsieh PF, Hou CW, Yao PW, Wu SP, Peng YF, Shen ML, Lin CH, Chao YY, Chang MH, Jeng KC: Sesamin ameliorates oxidative stress and mortality in kainic acid-induced status epilepticus by inhibition of MAPK and COX-2 activation. J Neuroinflammation 2011;8:57.

15 Su S, Li Q, Liu Y, Xiong C, Li J, Zhang R, Niu Y, Zhao L, Wang Y, Guo H: Sesamin ameliorates doxorubicininduced cardiotoxicity: involvement of Sirt1 and Mn-SOD pathway. Toxicol Lett 2014;224:257-263.

-16 Periasamy S, Hsu DZ, Chang PC, Liu MY: Sesame oil attenuates nutritional fibrosing steatohepatitis by modulating matrix metalloproteinases-2, 9 and PPAR-gamma. J Nutr Biochem 2014;25:337-344.

17 Ji YX, Zhang P, Zhang XJ, Zhao YC, Deng KQ Jiang X, Wang PX, Huang Z, Li H: The ubiquitin E3 ligase TRAF6 exacerbates pathological cardiac hypertrophy via TAK1-dependent signalling. Nat Commun 2016;7:11267.

18 Bian Z, Cai J, Shen DF, Chen L, Yan L, Tang Q, Li H: Cellular repressor of E1A-stimulated genes attenuates cardiac hypertrophy and fibrosis. J Cell Mol Med 2009;13:1302-1313.

19 Barisic S, Strozyk E, Peters N, Walczak H, Kulms D: Identification of PP2A as a crucial regulator of the NFkappaB feedback loop: its inhibition by UVB turns NF-kappaB into a pro-apoptotic factor. Cell Death Differ 2008;15:1681-1690.

20 Liu Y, Shen Y, Zhu J, Liu M, Li X, Chen Y, Kong X, Song G, Qian L: Cardiac-specific PID1 overexpression enhances pressure overload-induced cardiac hypertrophy in mice. Cell Physiol Biochem 2015;35:19751985.

21 Heineke J, Molkentin JD: Regulation of cardiac hypertrophy by intracellular signalling pathways. Nat Rev Mol Cell Biol 2006; 7:589-600.

-22 Koitabashi N, Danner T, Zaiman AL, Pinto YM, Rowell J, Mankowski J, Zhang D, Nakamura T, Takimoto E, Kass DA: Pivotal role of cardiomyocyte TGF-beta signaling in the murine pathological response to sustained pressure overload. J Clin Invest 2011;121:2301-2312.

-23 Liu RM, Gaston Pravia KA: Oxidative stress and glutathione in TGF-beta-mediated fibrogenesis. Free Radic Biol Med 2010;48:1-15.

24 Liu Z, Qiao Q, Sun Y, Chen Y, Ren B, Liu X: Sesamol ameliorates diet-induced obesity in C57BL/6J mice and suppresses adipogenesis in 3T3-L1 cells via regulating mitochondria-lipid metabolism. Mol Nutr Food Res $2017 ; 61$.

25 Giralt A, Hondares E, Villena JA, Ribas F, Diaz-Delfin J, Giralt M, Iglesias R, Villarroya F: Peroxisome proliferator-activated receptor-gamma coactivator-1alpha controls transcription of the Sirt3 gene, an essential component of the thermogenic brown adipocyte phenotype. J Biol Chem 2011;286:16958-16966.

-26 Sundaresan NR, Gupta M, Kim G, Rajamohan SB, Isbatan A, Gupta MP: Sirt3 blocks the cardiac hypertrophic response by augmenting Foxo3a-dependent antioxidant defense mechanisms in mice. J Clin Invest 2009;119:2758-2771.

27 Takimoto E, Kass DA: Role of oxidative stress in cardiac hypertrophy and remodeling. Hypertension 2007;49:241-248.

-28 Luo YX, Tang X, An XZ, Xie XM, Chen XF, Zhao X, Hao DL, Chen HZ, Liu DP: SIRT4 accelerates Ang II-induced pathological cardiac hypertrophy by inhibiting manganese superoxide dismutase activity. Eur Heart J 2017;38:1389-1398.

29 Kumano T, Fujiki E, Hashimoto Y, Kobayashi M: Discovery of a sesamin-metabolizing microorganism and a new enzyme. Proc Natl Acad Sci U S A 2016;113:9087-9092.

-30 Li WX, Kong X, Zhang JX, Yang JR: Long-term intake of sesamin improves left ventricular remodelling in spontaneously hypertensive rats. Food Funct 2013;4:453-460.

-31 Zhao M, Zheng S, Yang J, Wu Y, Ren Y, Kong X, Li W, Xuan J: Suppression of TGF-beta1/Smad signaling pathway by sesamin contributes to the attenuation of myocardial fibrosis in spontaneously hypertensive rats. PLoS One 2015;10:e0121312.

-32 Noguchi T, Ikeda K, Sasaki Y, Yamamoto J, Seki J, Yamagata K, Nara Y, Hara H, Kakuta H, Yamori Y: Effects of vitamin E and sesamin on hypertension and cerebral thrombogenesis in stroke-prone spontaneously hypertensive rats. Hypertens Res 2001;24:735-742.

-33 Zeisberg EM, Tarnavski O, Zeisberg M, Dorfman AL, McMullen JR, Gustafsson E, Chandraker A, Yuan X, Pu WT, Roberts AB, Neilson EG, Sayegh MH, Izumo S, Kalluri R: Endothelial-to-mesenchymal transition contributes to cardiac fibrosis. Nat Med 2007;13:952-961. 


\section{Cellular Physiology Cell Physiol Biochem 2017;44:2212-2227 \begin{tabular}{l|l} 
DOI: 10.1159/000486026 & $\begin{array}{l}\text { O 2017 The Author(s). Published by S. Karger AG, Basel } \\
\text { www.karger.com/cpb }\end{array}$
\end{tabular} \\ Fan et al.: Sesamin Attenuates Cardiac Remodeling}

-34 Lin CH, Shen ML, Kao ST, Wu DC: The effect of sesamin on airway fibrosis in vitro and in vivo. Int Immunopharmacol 2014;22:141-150.

-35 Rodriguez-Vita J, Sanchez-Lopez E, Esteban V, Ruperez M, Egido J, Ruiz-Ortega M: Angiotensin II activates the Smad pathway in vascular smooth muscle cells by a transforming growth factor-beta-independent mechanism. Circulation 2005;111:2509-2517.

-36 Li P, Wang D, Lucas J, Oparil S, Xing D, Cao X, Novak L, Renfrow MB, Chen YF: Atrial natriuretic peptide inhibits transforming growth factor beta-induced Smad signaling and myofibroblast transformation in mouse cardiac fibroblasts. Circ Res 2008;102:185-192.

-37 Sadoshima J, Montagne O, Wang Q, Yang G, Warden J, Liu J, Takagi G, Karoor V, Hong C, Johnson GL, Vatner DE, Vatner SF: The MEKK1-JNK pathway plays a protective role in pressure overload but does not mediate cardiac hypertrophy. J Clin Invest 2002;110:271-279.

38 Qi HP, Wang Y, Zhang QH, Guo J, Li L, Cao YG, Li SZ, Li XL, Shi MM, Xu W, Li BY, Sun HL: Activation of peroxisome proliferator-activated receptor gamma (PPARgamma) through NF-kappaB/Brg1 and TGFbeta1 pathways attenuates cardiac remodeling in pressure-overloaded rat hearts. Cell Physiol Biochem 2015;35:899-912.

-39 Hayden MS, Ghosh S: Shared principles in NF-kappaB signaling. Cell 2008;132:344-362.

40 Giordano FJ: Oxygen, oxidative stress, hypoxia, and heart failure. J Clin Invest 2005;115:500-508.

41 Nakamura K, Fushimi K, Kouchi H, Mihara K, Miyazaki M, Ohe T, Namba M: Inhibitory effects of antioxidants on neonatal rat cardiac myocyte hypertrophy induced by tumor necrosis factor-alpha and angiotensin II. Circulation 1998;98:794-799.

42 Shih NL, Cheng TH, Loh SH, Cheng PY, Wang DL, Chen YS, Liu SH, Liew CC, Chen JJ: Reactive oxygen species modulate angiotensin II-induced beta-myosin heavy chain gene expression via Ras/Raf/extracellular signal-regulated kinase pathway in neonatal rat cardiomyocytes. Biochem Biophys Res Commun 2001;283:143-148.

43 Date MO, Morita T, Yamashita N, Nishida K, Yamaguchi O, Higuchi Y, Hirotani S, Matsumura Y, Hori M, Tada M, Otsu K: The antioxidant N-2-mercaptopropionyl glycine attenuates left ventricular hypertrophy in in vivo murine pressure-overload model. J Am Coll Cardiol 2002;39:907-912.

44 Kong X, Wang R, Xue Y, Liu X, Zhang H, Chen Y, Fang F, Chang Y: Sirtuin 3, a new target of PGC-1alpha, plays an important role in the suppression of ROS and mitochondrial biogenesis. PLoS One 2010;5:e11707.

45 Arany Z, He H, Lin J, Hoyer K, Handschin C, Toka O, Ahmad F, Matsui T, Chin S, Wu PH, Rybkin, II, Shelton JM, Manieri M, Cinti S, Schoen FJ, Bassel-Duby R, Rosenzweig A, Ingwall JS, Spiegelman BM: Transcriptional coactivator PGC-1 alpha controls the energy state and contractile function of cardiac muscle. Cell Metab 2005;1:259-271. 